\title{
Spondyloepiphyseal dysplasia, Reardon type
}

INSERM

\section{Source}

INSERM. (1999). Orphanet: an online rare disease and orphan drug data base. Spondyloepiphyseal dysplasia, Reardon type. ORPHA:163662

Spondyloepiphyseal dysplasia, Reardon type is an extremely rare type of spondyloepiphyseal dysplasia (see this term) described in several members of a single family to date and characterized by short stature, vertebral and femoral abnormalities, cervical instability and neurologic manifestations secondary to anomalies of the odontoid process. 